\title{
ORAL COLONIZATION BY YEASTS IN HIV-POSITIVE PATIENTS IN BRAZIL
}

Juliana C. JUNQUEIRA(1), Simone F. G. VILELA(1), Rodnei D. ROSSONI(1), Júnia O. BARBOSA(1), Anna Carolina B. P. COSTA(1), Vanessa M. C. RASTEIRO(1), Jamal M. A. H. SULEIMAN(2) \& Antonio Olavo C. JORGE(1)

\begin{abstract}
SUMMARY
Introduction: In HIV-infected patients, colonization of the oral cavity by potential pathogenic yeast may lead to development of systemic fungemia. We evaluated the prevalence of yeast in the oral cavity of Brazilian HIV-positive patients and verified whether or not the species characterized were enzymatically active. Furthermore, the species identified were tested for their susceptibility to antifungal treatment. Methods: Patient saliva and oropharyngeal candidiasis samples were collected from 60 seropositive HIV patients and identified by the API20C system. Enzymatic activity was evaluated by the production of proteinase and phospholipase. Susceptibility to antifungal treatments were determined using the broth microdilution method. Results: the most commonly isolated species were C. albicans (51.56\%) followed by non-albicans Candida species (43.73\%), Trichosporon mucoides (3.12\%) and Kodamaea ohmeri $(1.56 \%)$. Oral colonization by association of different species was observed in $42 \%$ of the patients. Enzymatic activity was verified in most of species isolated, except for C. glabrata, C. lusitaniae and C. guilliermondii. Resistance to Fluconazole and Amphotericin B was observed in isolates of C. albicans, C. glabrata, C. parapsilosis, C. krusei, and K. ohmeri. Conclusion: HIV-positive patients are orally colonized by single or multiple species of yeast that are occasionally resistant to Fluconazole or Amphotericin B.
\end{abstract}

KEYWORDS: Acquired immunodeficiency syndrome; Candida; Trichosporon mucoides; Kodamaea ohmeri; Colonization.

\section{INTRODUCTION}

Candida spp. colonizes skin and mucosal surfaces of the genital and intestinal tracts as well the oral cavity under normal healthy conditions ${ }^{29}$. However, under immunocompromising conditions, such as when a patient is infected with human immunodeficiency virus (HIV), the colonization may grow out of control and rapidly turn into a symptomatic infection ${ }^{39}$. Protection against yeast conversion from a passive colonizer to an invasive pathogen is provided by both systemic and local immunity. T-helper type 1 (Th1) immunity provided by CD4+ T-lymphocytes is a critical component of that protection, however secondary defense is also provided by CD8+ T-lymphocytes and epithelial cells through a variety of mechanisms previously described ${ }^{39}$.

In fact, oropharyngeal candidiasis (OPC) is the most frequent opportunistic infection encountered in HIV-infected individuals. The disease occurs in up to $90 \%$ of patients during the course of HIV infection $^{3}$. The occurrence of OPC is associated with CD4+ T-lymphocyte levels below 200 cells $/ \mathrm{mm}^{3}$, high HIV viral load and disease progression. The prolonged course of HIV infection predisposes these patients to recurrent episodes of OPC that can increase in frequency and severity during the course of HIV disease progression ${ }^{3,13}$.

Several virulence factors contribute to the pathogenicity of Candida spp. including the ability to change cell morphology, a capacity to adhere to epithelial cells as well as the potential to secrete extracellular enzymes such as phospholipases and aspartyl proteinases ${ }^{6,22,35}$.

Phospholipases participate in the breakdown of phospholipids in host cell membranes while secretory aspartyl proteinases degrade several physiologically important substrates such as albumin, immunoglobulin and skin proteins, contributing to tissue penetration by Candida spp. and subsequent invasion of the host during the process of infection ${ }^{11,12,14,21}$.

C. albicans is the predominant species associated with mucosal and systemic fungal infections from yeast ${ }^{18,26}$. Nevertheless, the epidemiology of yeast infection is rapidly evolving and non-albicans Candida species as well as rare yeasts have emerged as major opportunistic pathogens. The most common non-albicans Candida species are $C$. glabrata, $C$. parapsilosis, C. tropicalis and C. krusei which have been frequently isolated from oral and systemic candidiasis. Other yeasts that are less common than Candida have been associated with life-threatening infections in immunocompromised hosts, such as Trichosporon, Rhodotorula, Non-neoformans Cryptococcus species, Geotrichum, Hansenula anomala ${ }^{13}$ and Kodamaea ohmeri ${ }^{17,37}$.

Although the importance of these emerging opportunist yeasts is recognized, little is known about their epidemiological traits,

(1) Department of Biosciences and Oral Diagnosis, Univ Estadual Paulista/UNESP, 12245-000 São José dos Campos, SP, Brazil.

(2) Emílio Ribas Institute of Infectious Diseases, 01246-900 São Paulo, SP, Brazil.

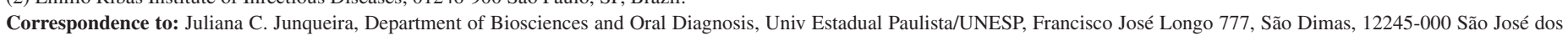
Campos, SP, Brasil, Tel: +55 12 39479033, Fax: +55 12 39479010. E-mail: juliana@ fosjc.unesp.br 
JUNQUEIRA, J.C; VILELA, S.F.G.; ROSSONI, R.D.; BARBOSA, J.O.; COSTA, A.C.B.P.; RASTEIRO V.M.C.; SULEIMAN, J.M.A.H. \& JORGE, A.O.C. - Oral colonization by yeasts in HIV-positive patients in Brazil. Rev. Inst. Med. Trop. Sao Paulo, 54(1): 17-24, 2012.

virulence factors and susceptibility to antifungal treatment. In the present study, we evaluated the prevalence of pathogenic yeast from saliva and oropharyngeal candidiasis of HIV-positive patients and correlated these data with CD4+ lymphocyte counts. Additionally, we tested the phospholipase and proteinase activity of Candida spp. and non-Candida species identified, as well as their susceptibilities to antifungal treatment.

\section{MATERIALS AND METHODS}

Subjects: A total of 60 seropositive HIV patients (diagnosed by ELISA and Western-blot) under anti-retroviral therapy at the Emílio Ribas Institute of Infectious Diseases (São Paulo, Brasil) were included in this study. All of the patients agreed to participate in the study by signing an informed consent form approved by the Research Ethics Committee of the São José dos Campos School of Dentistry/UNESP (protocol 051/2009-PH/CEP) and Ethics Committee of the Emílio Ribas Institute of Infectious Diseases (protocol 274/2009).

Participants were recruited from September 2009 to May 2010 and recent data on CD4+ T-lymphocyte counts were obtained from their medical records. Of 60 patients studied, seven patients $(11.66 \%)$ presented symptoms of oropharyngeal candidiasis and 53 did not have such lesions in the oral cavity $(88.33 \%)$.

Sample collection: In the patients with oropharyngeal candidiasis, samples were obtained by firmly swabbing the lesion site with a sterile cotton wool swab. The swabs were cultured on Sabouraud dextrose agar (Difco, Detroit, USA) supplemented with chloramphenicol (100 $\mu \mathrm{g} / \mathrm{mL})$ and chromogenic HiCrome Candida agar (Himedia, Munbai, India). HiCrome Candida agar is a differential culture medium that is claimed to facilitate the isolation and identification of C. albicans, C. tropicalis, C. kruse $i$ and $C$. glabrata. The samples were then incubated aerobically at $37^{\circ} \mathrm{C}$ for 48 hours.

In patients without oral candidiasis, samples from saliva were collected by oral rinses in buffered phosphate saline (PBS, $0.1 \mathrm{M}, \mathrm{pH} 7.2$ ) for one min. The samples were centrifuged for $10 \mathrm{~min}$ at $8,000 \mathrm{~g}$ and the supernatant was discarded. Next, $2.5 \mathrm{~mL}$ of PBS was added to the pellet. Ten-fold serial dilutions were carried out and aliquots of $100 \mu \mathrm{L}$ were seeded on Sabouraud dextrose agar (Difco, Detroit, USA) and HiCrome Candida agar (Himedia, Munbai, India). After 48 hours of incubation at $37{ }^{\circ} \mathrm{C}$ the colony forming units $(\mathrm{CFU} / \mathrm{mL})$ were counted. The positive and negative yeast cultures from saliva were compared for variables of age and CD4+ lymphocyte counts using a Student's $t$ test by the Minitab Program. A probability $(p)$ of $<0.05$ was considered significant.

Yeast isolates were selected for species level identification by colony morphology on Sabouraud agar and colony color on HiCrome Candida agar. In clinical samples with different colonies, one isolate of each colony was obtained for species identification.

Yeast isolates identification: Identification of the species of the isolates was performed by standard methods (germ-tube formation, cornmeal agar chlamydospore and hyphae production) and by the API20C system (BioMérieux, Paris, France) for sugar assimilation. Isolates phenotypically identified as $C$. albicans or $C$. dubliniensis were confirmed using a multiplex polymerase chain reaction (PCR) procedure, as previously described ${ }^{2,32}$. For PCR, two pairs of primers were used: two universal primers, Uni-f: 50-GCATATCAATAAGCGGAGGAAAA-30 and Uni-r: 50-GGTCCGTGTTTCAAGACG-30; and two C. dubliniensisspecific ones, DUBF Act-f: 50GTATTTGTCGTTCCCCTTTC-30 e DUBR Act-r: 50-GTGTTGTGTGCACTAACGTC-30.

Phospholipase and proteinase activity: Phospholipase production in the yeast isolates was assayed using the egg-yolk agar plate method of PRICE et al. ${ }^{30}$. Sabouraud dextrose agar plates containing $57.3 \mathrm{~g}$ $\mathrm{NaCl}, 0.55 \mathrm{~g} \mathrm{CaCl} 2$ and $8 \%$ sterile egg-yolk emulsion were used. Test strains were spot inoculated and plates were incubated at $37{ }^{\circ} \mathrm{C}$ for up to five days. Each isolate was tested in duplicate. The diameter of each colony and the total diameter of the colony and precipitation zone $(\mathrm{Pz})$ were measured. Furthermore, phospholipase activity was scored. The Pz value, representing the ratio of colony diameter alone to the diameter of the colony plus precipitation zone, was determined. The results were classified as negative $(\mathrm{Pz}=1 \mathrm{~cm})$, positive $(0.64 \mathrm{~cm} \geq \mathrm{Pz}<1 \mathrm{~cm})$ and strongly positive $(\mathrm{Pz}<0.64 \mathrm{~cm})$. By this classification system, a high $\mathrm{Pz}$ value indicates low enzymatic activity.

The isolates were tested for proteinase secretion in bovine serum albumin (BSA) agar that contained yeast carbon base $(1.17 \%)$; yeast extract $(0.01 \%)$ and BSA $(0.2 \%)$, according RUCHEL et al. ${ }^{33}$. The medium was adjusted to $\mathrm{pH} 5.0$, sterilized by filtration and added to autoclaved $2 \%$ agar. Test strains were spot inoculated and plates were incubated at $37^{\circ} \mathrm{C}$ for up to five days. Each isolate was tested in duplicate. Post-incubation, plates were stained with $0.5 \%$ amido black and the zone of clearance around the colony was recorded. Scoring was carried out by determination of the proteinase zone $(\mathrm{Pz})$ value, by the same method used to determine phospholipase activity.

Antifungal susceptibility testing: Susceptibility patterns of the yeast isolates to nystatin, fluconazole and amphotericin B (Sigma-Aldrich, Steinheim, Germany) were determined by a broth-microdilution assay, in duplicate, according to document M27-A2 of the Clinical and Laboratory Standards Institute (CLSI) ${ }^{4}$.

Fluconazole was dissolved in sterile distilled water while nystatin and amphotericin B were dissolved in dimethyl sulfoxide (SigmaAldrich, Steinheim, Germany) to make stock solutions. RPMI 1640 medium with L-glutamine without sodium bicarbonate and buffered with morpholinepropanesulfonic acid (MOPS) at 0.165 M (Sigma-Aldrich, Steinheim, Germany) was used as a test medium. The range of fluconazole concentrations tested was from 0.125 to $64 \mu \mathrm{g} / \mathrm{mL}$, while amphotericin B and nystatin were tested within the range of 0.031 to $16 \mu \mathrm{g} / \mathrm{mL}$.

The inoculum of Candida strains was grown in Sabouraud dextrose agar for $48 \mathrm{~h}$ at $35{ }^{\circ} \mathrm{C}$. This solution was prepared in $5 \mathrm{~mL}$ sterile saline $(0.85 \%)$ and the cellular density at 0.284 was adjusted on a spectrophotometer (B582, Micronal, São Paulo, Brazil) at wavelength $=530 \mathrm{~nm}$, resulting in a standard solution with $1 \times 10^{6}$ cells $/ \mathrm{mL}$. The standard solution was diluted in RPMI 1640 in order to obtain a final concentration of $1 \times 10^{3}$ to $5 \times 10^{3}$ cells $/ \mathrm{mL}$.

The microplates were incubated at $37^{\circ} \mathrm{C}$ for 48 hours. The Minimal Inhibitory Concentration (MIC) for fluconazole was defined by the lowest concentration of the drug resulting in an $80 \%$ reduction in turbidity, in comparison with drug-free growth control, and for amphotericin B and 


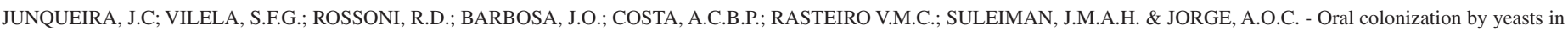
HIV-positive patients in Brazil. Rev. Inst. Med. Trop. Sao Paulo, 54(1): 17-24, 2012.

nystatin the MIC values were defined by the lowest concentration of drug resulting in complete inhibition of visible growth. Results are expressed as a range of minimum and maximum MIC values as well as by the values of $\mathrm{MIC}_{50}$ (the MIC at which $50 \%$ of the isolates are inhibited) and $\mathrm{MIC}_{90}$ (the MIC at which $90 \%$ of the isolates are inhibited).

The following resistance breakpoints were used according to CLSI guidelines for all yeasts isolated. For fluconazole, MICs of $\leq 8 \mu \mathrm{g} / \mathrm{mL}$ were considered to be susceptible, $16-32 \mu \mathrm{g} / \mathrm{mL}$ to be susceptible but dose-dependent and $\geq 64 \mu \mathrm{g} / \mathrm{mL}$ to be resistant. There were no CLSI breakpoints defined for nystatin and amphotericin B. For susceptibility to amphotericin B, the breakpoint established by YANG et al. ${ }^{41}$ was adopted as follows: isolates with MIC $\geq 2 \mu \mathrm{g} / \mathrm{mL}$ were considered to be resistant, and those with $\mathrm{MIC} \leq 1 \mu \mathrm{g} / \mathrm{mL}$ were susceptible.

\section{RESULTS}

Patient data: Of the 60 patients examined, 39 (65\%) were men and $21(35 \%)$ were women. The mean age was 43 years, and the total range of ages was from 29 to 63 years. Their CD4+ lymphocyte counts ranged from 97 to 2021 cells $/ \mathrm{mm}^{3}$ with a mean count of 739 cells $/ \mathrm{mm}^{3}$.

Of 53 patients without clinical lesions from candidiasis in the oral cavity, $33(62 \%)$ presented positive cultures for yeast in the saliva and $20(38 \%)$ showed negative cultures. The number of colony-forming units ranged from 0 to $72,000 \mathrm{CFU} / \mathrm{mL}$ with a mean value of 5,230 $\mathrm{CFU} / \mathrm{mL}$ and a median value of $300 \mathrm{CFU} / \mathrm{mL}$. The patient age and CD4+ lymphocyte counts were compared between groups with positive and negative cultures. This analysis indicated no significant statistical difference between the groups (Table 1).

Prevalence and distribution of isolates: One isolate of each species from the same patient was analyzed with a total of 64 isolates obtained. Fifty-one isolates were obtained from the saliva of 33 patients without oral candidiasis and 13 from seven patients with oropharyngeal candidiasis.
Table 1

Patient age and CD4+ T-lymphocyte counts indicating both positive and negative cultures from the saliva of $53 \mathrm{HIV}$-positive patients

\begin{tabular}{lccc}
\hline & \multicolumn{2}{c}{ Yeast Culture } & \\
\cline { 2 - 3 } Variables & $\begin{array}{c}\text { Positive } \\
(\mathrm{n}=33)\end{array}$ & $\begin{array}{c}\text { Negative } \\
(\mathrm{n}=20)\end{array}$ & $p$ value \\
\hline Age & $44.4 \pm 8.1$ & $41.4 \pm 7.0$ & 0.158 \\
CD4+ lymphocytes & $762.6 \pm 452.1$ & $700.9 \pm 379.8$ & 0.597 \\
\hline
\end{tabular}

Student $t$ test $(p<0.05)$

C. albicans was the most frequently isolated species followed by $C$. glabrata. The distribution of all isolated species is shown in Table 2.

Of the 40 patients with positive yeast cultures ( 33 patients without oral candidiasis and seven patients with oropharyngeal candidiasis), 23 (58\%) presented oral colonization or infection by single yeast species (19 from saliva and four from OPC) and 17 (42\%) showed colonization by association of multiple species (Table 3 ).

Phospholipase and proteinase activity of isolates: Phospholipase activity was observed in all isolates of $C$. albicans, $C$. dubliniensis, $C$. tropicalis, C. krusei, C. novergensis, T. mucoides and K. ohmeri. Proteinase activity was found in all isolates of $C$. albicans, $C$. parapsilosis and C. dubliniensis. However, C. glabrata, C. lusitaniae and $C$. guilliermondii were negative for phospholipase and proteinase activity (Table 4).

Antifungal susceptibility of yeast isolates: The range of susceptibilities to Fluconazole and Amphotericin B is summarized in Table 5. Most isolates were susceptible to Fluconazole (81.25\%) and Amphotericin B (93.75\%). The resistance to Fluconazole was observed in nine (27\%) isolates of $C$. albicans, one isolate of $C$. glabrata, one isolate of $C$. krusei and one isolate

Table 2

Frequency of yeast species isolated from saliva and oropharyngeal candidiasis (OPC) in HIV-positive patients

\begin{tabular}{|c|c|c|c|c|c|c|}
\hline \multirow{3}{*}{ Yeast species } & \multicolumn{6}{|c|}{ Frequency (\%) } \\
\hline & \multicolumn{2}{|c|}{ All isolates $(n=64)$} & \multicolumn{2}{|c|}{ Saliva $(\mathrm{n}=51)$} & \multicolumn{2}{|c|}{ OPC $(n=13)$} \\
\hline & $\mathrm{n}$ & $\%$ & $\mathrm{n}$ & $\%$ & $\mathrm{n}$ & $\%$ \\
\hline C. albicans & 33 & 51.56 & 25 & 49.00 & 8 & 61.53 \\
\hline C. glabrata & 10 & 15.62 & 8 & 15.68 & 2 & 15.38 \\
\hline C. parapsilosis & 5 & 7.81 & 4 & 7.84 & 1 & 7.69 \\
\hline C. dubliniensis & 4 & 6.25 & 4 & 7.84 & - & - \\
\hline C. tropicalis & 4 & 6.25 & 3 & 5.88 & 1 & 7.69 \\
\hline C. krusei & 2 & 3.12 & 1 & 1.96 & 1 & 7.69 \\
\hline C. lusitaniae & 1 & 1.56 & 1 & 1.96 & - & - \\
\hline C. guilliermondii & 1 & 1.56 & 1 & 1.96 & - & - \\
\hline C. norvegensis & 1 & 1.56 & 1 & 1.96 & - & - \\
\hline T. mucoides & 2 & 3.12 & 2 & 3.92 & - & - \\
\hline K. ohmeri & 1 & 1.56 & 1 & 1.96 & - & - \\
\hline
\end{tabular}


of $K$. ohmeri. The resistance to Amphotericin B was verified in three isolates of $C$. parapsilosis and one isolate of $C$. krusei. The MIC to Nystatin was $4 \mu \mathrm{g} / \mathrm{mL}$ for all species studied, except for C. parapsilosis and C. krusei in which MICs ranged from 4 to $8 \mu \mathrm{g} / \mathrm{mL}$.

\section{DISCUSSION}

Although the incidence of oropharyngeal candidiasis has declined for HIV-infected patients with access to antiretroviral therapy (ART), it

Table 3

Number of HIV-positive patients colonized by multiple yeast-species from saliva and oropharyngeal candidiasis (OPC)

\begin{tabular}{lcc}
\hline & \multicolumn{2}{c}{ Number of Patients } \\
\cline { 2 - 3 } Association of different species & $\begin{array}{c}\text { Saliva } \\
(\mathrm{n}=33)\end{array}$ & $\begin{array}{c}\mathrm{OPC} \\
(\mathrm{n}=7)\end{array}$ \\
\hline C. albicans + C. glabrata & 4 & 1 \\
C. albicans + C. dubliniensis & 1 & - \\
C. albicans + C. tropicalis & 1 & 1 \\
C. albicans + T. mucoides & 1 & - \\
C. albicans + K. ohmeri & 1 & - \\
C. parapsilosis + C. glabrata & 1 & - \\
C. parapsilosis + C. dubliniensis & 1 & - \\
C. albicans + C. dubliniensis + & 1 & - \\
C. parapsilosis & 1 & - \\
C. albicans + C. novergensis + C. krusei & 1 & - \\
C. dublinienis + C. tropicalis + C. glabrata & 1 & - \\
C. glabrata + C. parapsilosis + T. mucoides & & \\
C. albicans + C. krusei + C. parapsilosis + & - & 1 \\
C. glabrata & & \\
\hline
\end{tabular}

remains a significant problem for those in locations with limited resources or those with a poor immunologic response, despite the ART treatment ${ }^{38}$. In this study, we evaluated $60 \mathrm{HIV}$-positive patients under anti-retroviral therapy. Seven patients had oropharyngeal candidiasis and 53 did not have candidiasis lesions.

Among the 53 patients without candidiasis, $62 \%$ were positive for oral carriage of yeast. These data are similar to epidemiological studies performed in Thailand ${ }^{10}$, India ${ }^{9}$ and Argentina ${ }^{20}$ that found respectively 61,68 and $72 \%$ of $\mathrm{HIV}$-positive patients to be subject to oral colonization by yeast. However, more instances of yeast carriage among HIV-positive patients were observed in Turkey, with $82 \%$ of patients positive for yeast in the oral cavity ${ }^{7}$. Some studies showed that the prevalence of yeasts in the oral cavity of HIV-negative individuals ranged from 46 to $56 \% \%^{2,32}$.

The number of colony-forming units in the saliva of HIV-positive patients without clinical lesions showed a median value of $300 \mathrm{CFU} /$ $\mathrm{mL}$. BACK-BRITO et al. $^{2}$ detected more cases of Candida spp. in the oral cavity of HIV-positive patients (median value of $860 \mathrm{CFU} / \mathrm{mL}$ and interquartile range of $3250 \mathrm{CFU} / \mathrm{mL}$ ) in relation to the control group (median value of $0 \mathrm{CFU} / \mathrm{mL}$ and interquartile range of $480 \mathrm{CFU} / \mathrm{mL}$ ).

The absolute CD4+ T-lymphocyte count has traditionally been cited as the greatest risk factor for switching the status of asymptomatic yeast colonization to the development of oropharyngeal candidiasis, and current guidelines suggest an increased risk once the CD4+ T-lymphocyte count falls to $<200$ cells $/ \mu \mathrm{L}^{39}$. In this study, we found no difference in the CD4+ T-lymphocyte counts between patients positive or negative for oral carriage of yeast. Other studies have also found no correlation between CD4+ T-lymphocyte counts and yeast colonization $^{2,7,19,20}$. On the other hand, BACK-BRITO et al. ${ }^{2}$ and YANG et $a l .{ }^{40}$ observed significantly lower yeast counts in patients with a lower viral load $(<400$ copies $/ \mathrm{mL}$ ), suggesting that viral load might be a higher risk factor for the occurrence of candidiasis as compared to the CD4+ T-lymphocyte count.

Table 4

Number of yeast isolates according to phospholipase and proteinase activity as determined by PRICE et al. (1982)

\begin{tabular}{|c|c|c|c|c|c|c|}
\hline \multirow{2}{*}{ Species (No. of isolates) } & \multicolumn{3}{|c|}{ Phospholipase activity } & \multicolumn{3}{|c|}{ Proteinase activity } \\
\hline & Negative & Positive & Strongly positive & Negative & Positive & Strongly positive \\
\hline C. albicans (33) & - & 15 & 18 & - & 16 & 17 \\
\hline C. glabrata (10) & 10 & - & - & 10 & - & - \\
\hline C. parapsilosis (5) & 5 & - & - & - & - & 5 \\
\hline C. dubliniensis (4) & - & 4 & - & - & 4 & - \\
\hline C. tropicalis (4) & - & 3 & 2 & 4 & - & - \\
\hline C. krusei (2) & - & 2 & - & 2 & - & - \\
\hline C. lusitaniae (1) & 1 & - & - & 1 & - & - \\
\hline C. guilliermondii (1) & 1 & - & - & 1 & - & - \\
\hline C. norvegensis (1) & - & 1 & - & 1 & - & - \\
\hline T. mucoides (2) & - & - & 2 & 2 & - & - \\
\hline K. ohmeri (1) & - & - & 1 & 1 & - & - \\
\hline
\end{tabular}


JUNQUEIRA, J.C; VILELA, S.F.G.; ROSSONI, R.D.; BARBOSA, J.O.; COSTA, A.C.B.P.; RASTEIRO V.M.C.; SULEIMAN, J.M.A.H. \& JORGE, A.O.C. - Oral colonization by yeasts in HIV-positive patients in Brazil. Rev. Inst. Med. Trop. Sao Paulo, 54(1): 17-24, 2012.

Table 5

Antifungal susceptibilities of yeast isolates as determined by the CLSI microdilution reference broth method

\begin{tabular}{|c|c|c|c|c|c|c|}
\hline \multirow{2}{*}{ Species (No. of isolates) } & \multicolumn{3}{|c|}{ Fluconazole $(\mu \mathrm{g} / \mathrm{mL})$} & \multicolumn{3}{|c|}{ Amphotericin B $(\mu \mathrm{g} / \mathrm{mL})$} \\
\hline & Range & $\mathrm{MIC}_{50}$ & $\mathrm{MIC}_{90}$ & Range & $\mathrm{MIC}_{50}$ & $\mathrm{MIC}_{90}$ \\
\hline C. albicans (33) & $0.125->64$ & 0.125 & $>64$ & $0.125-0.5$ & 0.25 & 0.25 \\
\hline C. glabrata (10) & $1->64$ & 4 & 8 & $0.25-0.5$ & 0.5 & 0.5 \\
\hline C. parapsilosis (5) & $0.5-64$ & 1 & 2 & $0.5-2$ & 0.5 & 2 \\
\hline C. dubliniensis (4) & $0.5-16$ & 0.5 & 1 & $0.125-0.25$ & 0.25 & 0.25 \\
\hline C. tropicalis (4) & $0.125-2$ & 1 & 1 & 0.25 & 0.25 & 0.25 \\
\hline C. krusei (2) & $32-64$ & 32 & 64 & $0.5-2$ & 0.5 & 2 \\
\hline C. lusitaniae (1) & 0.125 & 0.125 & 0.125 & 0.25 & 0.25 & 0.25 \\
\hline C. guilliermondii (1) & 2 & 2 & 2 & 0.25 & 0.25 & 0.25 \\
\hline C. norvegensis (1) & 32 & 32 & 32 & 0.5 & 0.5 & 0.5 \\
\hline T. mucoides (2) & $2-4$ & 2 & 4 & $0.25-0.5$ & 0.25 & 0.5 \\
\hline K. ohmeri (1) & $>64$ & $>64$ & $>64$ & 0.25 & 0.25 & 0.25 \\
\hline
\end{tabular}

In the present study, $C$. albicans was the most common species isolated in the saliva of patients both without clinical lesions (49\%) and oropharyngeal candidiasis (61\%). These results support previous studies performed in the oral cavity of HIV-positive patients ${ }^{3,13,27,40}$. Even though C. albicans was the most common species recovered, the non-albicans Candida species have become more recognized as a major source of infection. This hypothesis was supported by this study in which $49 \%$ of isolates were identified as non-albicans species.

Among non-albicans isolates, C. glabrata was the most frequently isolated species from the saliva of patients without clinical lesions and from oropharyngeal candidiasis. According to REDDING et al. ${ }^{31}, C$. glabrata has emerged as a notable pathogenic agent in oral mucosa, either as a co-infecting agent with $C$. albicans or as the sole detectable species from oral lesions. In addition, C. glabrata-associated oropharyngeal candidiasis infections in HIV-positive patients tend to be more severe and more difficult to treat than infections due solely to C. albicans.

Besides C. glabrata, other common non-albicans Candida species were isolated from the oral cavity including C. parapsilosis, C. tropicalis, C. krusei, C. lusitaniae, C. guilliermondii, and C. dubliniensis. C. dubliniensis was first isolated from oropharyngeal lesions in HIV-positive patients in Dublin. It is phenotypically very similar to C. albicans, producing both germ tubes and chlamydospores. Since the original description in 1995, it has been recovered from 25\% of HIV-positive Irish patients, with subsequent reports suggesting a worldwide distribution ${ }^{2}$. In this study, $C$. dubliniensis was identified in $6.25 \%$ of isolates. Previous findings indicated that the rate of $C$. dubliniensis oral isolates recovered from HIV-postive patients was $0.3 \%$ in Tanzania ${ }^{13}, 17 \%$ in United States of America ${ }^{39}$, and $20 \%$ in Argentina ${ }^{20}$.

In this study, rare yeast species including C. norvegensis, Kodamaea ohmeri and Trichosporon mucoides were also identified by API20C system. C. norvegensis was first isolated in Norway 70 years ago and appears to be a rare cause of human disease ${ }^{15}$. SANDVEN et al. ${ }^{34}$ identified a total of four invasive infections occurring between 1990 and 1996 and all isolates of $C$. norvegensis were fluconazole resistant, potentially indicating an inherent characteristic of the species. There are only two studies that report isolation of $C$. norvegensis from the oral cavity. Both studies were performed in Brazil with children ${ }^{23}$ and adults ${ }^{24}$ seropositive for HIV.

Kodamaeae (Pichia) ohmeri, a teleomorph of C. guilliermondii var. membranaefaciens, is an environmental strain commonly used in the food industry. However, it is also an emerging fungal pathogen, particularly in immunocompromised patients ${ }^{17}$. In 2010, SHANG et al. conducted a search of English medical literature from 1970 to 2008 and found 20 reported cases of $K$. ohmeri infection ${ }^{37}$. The isolation of $K$. ohmeri from the oral cavity was reported in only one study in which $K$. ohmeri was recovered from oropharyngeal candidiasis in Indian HIV-infected patients ${ }^{25}$. This species has been identified by the API 20C system and confirmed by ascospore formation or molecular identification, however in this study the identification of K. ohmeri was not confirmed by these analyses.

Trichosporon mucoides were isolated from the oral cavity of two patients in this study. This is the first study to describe the isolation of this species from the oral cavity. Trichosporon spp. predominantly cause superficial skin infections and scalp or pubic white piedra, but they can also cause invasive disease in immunocompromised individuals. Trichosporonosis, the deep-seated infection caused by this fungus, is an often fatal disease with a mortality rate of $80 \%^{16,28,36}$.

The transformation from harmless commensal yeast to virulent pathogen under the conditions of a dysfunctional host-defense system is attributable to an extensive repertoire of selectively expressed virulence determinants. Phospholipases and proteinases are considered to play an important role in Candida overgrowth, as these factors facilitate adherence, tissue penetration and subsequent invasion of the host $\mathrm{t}^{10}$. Phospholipase and proteinase production was found in $100 \%$ of $C$. albicans isolates during this study. However, MANE et al. ${ }^{21}$ verified production of phospholipase and proteinase in only $59 \%$ and $89.7 \%$, 
JUNQUEIRA, J.C; VILELA, S.F.G.; ROSSONI, R.D.; BARBOSA, J.O.; COSTA, A.C.B.P.; RASTEIRO V.M.C.; SULEIMAN, J.M.A.H. \& JORGE, A.O.C. - Oral colonization by yeasts in HIV-positive patients in Brazil. Rev. Inst. Med. Trop. Sao Paulo, 54(1): 17-24, 2012.

respectively, of C. albicans isolates obtained from HIV-positive patients with oral candidiasis.

Among the isolates of non-albicans species identified in this study, $39 \%$ showed phospholipase activity and $21 \%$ exhibited proteinase activity. Previous studies also reported that proteinases and phospholipases are produced at high rates in C. albicans, whilst non-albicans Candida species usually present low rates of these enzymes ${ }^{5,8}$. No isolates of $C$. glabrata, C. lusitaniae or C. guilliermondii exhibited enzymatic activity. Although C. glabrata presents a higher mortality rate compared with infection by other non-albicans Candida, this species presents a lack of enzymatic activity and low virulence in animal models of infection ${ }^{31}$. According to KRCMERY \& BARNES ${ }^{15}$, invasive $C$. glabrata infection occurs predominantly in the illest of patients, such as in the terminal stages of malignant disease. This phenomenon explains the somewhat higher overall mortality rate observed for $C$. glabrata in comparison with other non-albicans Candida species.

The present study is the first to describe phospholipase enzymatic activity by $K$. ohmeri and T. mucoides. Of note, these species were unable to produce proteinase. However, because these species were isolated from the oral cavity, it is necessary to design studies to evaluate their virulence in animal models of oral candidiasis.

Among the patients analyzed in this study, $42 \%$ had oral colonization or infections by association of Candida species, including two, three or four different species in the same patient. LUQUE et al. ${ }^{20}$ also observed that $59 \%$ of Argentinian HIV-positive patients carried two or three different species of yeast in their oral cavity. C. albicans and C. glabrata were the most frequently identified combination of yeast infections in our study. This combination was also reported in mixed candidemia by MICELI et al. ${ }^{26}$.

The emergence of yeasts other than C. albicans and of mixed infections suggests that the epidemiology of Candida infections is changing. Consequently these infections may require higher doses of antifungal treatments to resolve. The presence of more than one species of Candida in the oral mucosa may predispose patients to recurrent candidiasis, mainly caused by species resistant to antifungal treatments ${ }^{27,38}$.

In this study, some isolates of C. albicans (27\%), C. glabrata and $K$. ohmeri were resistant to Fluconazole and isolates of $C$. parapsilosis and C. kruse i were resistant to Amphotericin B. Meanwhile, C. parapsilosis and C. krusei showed the highest MICs for Nystatin (4 to $8 \mu \mathrm{g} / \mathrm{mL}$ ). Among clinical oral yeasts from $292 \mathrm{HIV}$-infected patients in Tanzania analyzed by HAMZA et al. ${ }^{13} 5 \%$ showed resistance to Fluconazole, including isolates of C. glabrata, C. tropicalis and C. krusei, and all isolates were susceptible to Amphotericin B. The MICs to Nystatin ranged from 2 to $8 \mu \mathrm{g} / \mathrm{mL}$ for non-albicans Candida species and from 2 to $16 \mu \mathrm{g} / \mathrm{mL}$ for $C$. albicans. BACK-BRITO et al. ${ }^{1}$ demonstrated that Amphothericin B, Fluconazole, Flucytosine, Nystatin and Ketoconazole showed good activity for most Candida isolates from the oral cavity of HIV-positive patients. However, variability in MIC values among isolates was observed, confirming the importance of susceptibility tests as a guide to the treatment of oral candidiasis.

We conclude that oral colonization and infection by yeasts in
Brazilian HIV-positive patients is composed of different species, including C. albicans, non-albicans Candida species and non-Candida species. Furthermore, these yeast species frequently form associations of two or more species and are resistant to Fluconazole or Amphotericin B treatment.

\section{RESUMO}

\section{Colonização oral por leveduras em pacientes HIV-positivos no Brasil}

Introdução: Em pacientes infectados pelo HIV, a colonização da cavidade bucal por leveduras patogênicas pode levar ao desenvolvimento de fungemias. No presente estudo, avaliamos a prevalência de leveduras na cavidade bucal de pacientes HIV-positivos e verificamos se as espécies isoladas foram enzimaticamente ativas. Além disso, as espécies identificadas foram testadas quanto à suscetibilidade a antifúngicos. Métodos: Amostras de saliva e de candidose orofaríngea foram coletadas de 60 pacientes soropositivos para HIV e identificados pelo sistema API20C. A atividade enzimática foi avaliada pela produção de proteinase e fosfolipase. A suscetibilidade a antifúngicos foi determinada utilizando o método de microdiluição em caldo. Resultados: As espécies mais comumente isoladas foram C. albicans (51,56\%), seguido por espécies de Candida não-albicans (43,73\%), Trichosporon mucoides $(3,12 \%)$ e Kodamaea ohmeri $(1,56 \%)$. A colonização bucal por associação de diferentes espécies foi observada em $42 \%$ dos pacientes. A atividade enzimática foi verificada na maioria das espécies isoladas, com exceção de $C$. glabrata, $C$. lusitaniae e $C$. guilliermondii. Resistência ao fluconazol e anfotericina B foi observada em isolados de C. albicans, C. glabrata, C. parapsilosis, C. krusei, e $K$. ohmeri. Conclusão: Os pacientes HIV-positivos são colonizados por espécies únicas ou múltiplas de levedura que ocasionalmente são resistentes ao fluconazol ou anfotericina B.

\section{ACKNOWLEDGEMENTS}

This study was supported by the São Paulo Council of Research - FAPESP, Brazil (Grant $n^{\circ}$ 09/52283-0) and Universidade Estadual Paulista - PROPE/UNESP.

\section{CONFLICT OF INTERESTS}

The authors declare that they have no competing interests.

\section{AUTHORS' CONTRIBUTIONS}

JCJ and AOCJ designed the study. JMAHS collected the data. ACPBC, JCJ, JOB, RDR, SFGV and VMCR performed the technique. JCJ made the interpretation of statistical analyses. JCJ and AOCJ wrote the paper with input from all of the authors, who each approved the final version.

\section{ETHICAL APPROVAL}

The study was approved by the Research Ethics Committee of the São José dos Campos School of Dentistry/UNESP (protocol 051/2009-PH/ CEP) and Ethics Committee of the Emílio Ribas Institute of Infectious Diseases (protocol 274/2009). 


\section{REFERENCES}

1. Back-Brito GN, Inocêncio ACS, Querido SMR, Jorge AOC, Koga-Ito CY. In vitro antifungal susceptibility of Candida spp. oral isolates from HIV-positive patients and control individuals. Braz Oral Res. 2010;25:28-33.

2. Back-Brito GN, Mota AJ, Vasconcellos TC, Querido SM, Jorge AO, Reis AS, et al. Frequency of Candida spp. in the oral cavity of Brazilian HIV-positive patients and correlation with CD4 cell counts and viral load. Mycopathologia. 2009;167:81-7.

3. Badiee P, Alborzi A, Davarpanah MA, Shakiba E. Distributions and antifungal susceptibility of Candida species from mucosal sites in HIV positive patients. Arch Iran Med. 2010;13:282-7.

4. Clinical and Laboratory Standards Institute. Reference method for broth dilution antifungal susceptibility testing of yeasts: approved standard. M27-A2. Wayne; 2002.

5. Costa CR, Passos XS, Sousa LK, Lucena AP, Fernandes FO, Silva RM. Differences in exoenzyme production and adherence ability of Candida spp. isolates from catheter, blood and oral cavity. Rev Inst Med Trop Sao Paulo. 2010;52:139-43.

6. D’Eça Júnior A, Silva AF, Rosa FC, Monteiro SG, de Maria Silva Figueiredo P, de Andrade Monteiro C. In vitro differential activity of phospholipases and acid proteinases of clinical isolates of Candida. Rev Soc Bras Med Trop. 2011;44:334-8.

7. Erköse G, Erturan Z. Oral Candida colonization of human immunodeficiency virus infected subjects in Turkey and its relation with viral load and CD4+ T-lymphocyte count. Mycoses. 2007;50:485-90.

8. Gokce G, Cerikcioglu N, Yagci A. Acid proteinase, phospholipase, and biofilm production of Candida species isolated from blood cultures. Mycopathologia. 2007;164:265-9.

9. Gugnani HC, Becker K, Fegeler W, Basu S, Chattopadhya D, Baveja U, et al. Oropharyngeal carriage of Candida species in HIV-infected patients in India. Mycoses. 2003;46:299-306.

10. Jainkittivong A, Lin AL, Johnson DA, Langlais RP, Yeh CK. Salivary secretion, mucin concentrations and Candida carriage in HIV-infected patients. Oral Dis. 2009;15:22934.

11. Jayatilake JA, Samaranayake YH, Samaranayake LP. An ultrastructural and a cytochemical study of candidal invasion of reconstituted human oral epithelium. J Oral Pathol Med. 2005;34:240-6.

12. Junqueira JC, Colombo CE, Martins JS, Koga-Ito CY, Carvalho YR, Jorge AO Experimental candidosis and recovery of Candida albicans from the oral cavity of ovariectomized rats. Microbiol Immunol. 2005;49:199-207.

13. Hamza OJ, Matee MI, Moshi MJ, Simon EN, Mugusi F, Mikx FH, et al. Species distribution and in vitro antifungal susceptibility of oral yeast isolates from Tanzanian HIV-infected patients with primary and recurrent oropharyngeal candidiasis. BMC Microbiol. 2008;8:135

14. Höfling JF, Mardegan RC, Anibal PC, Furletti VF, Foglio MA. Evaluation of antifungal activity of medicinal plant extracts against oral Candida albicans and proteinases. Mycopathologia. 2011;172:117-24.

15. Krcmery V, Barnes AJ. Non-albicans Candida spp. causing fungaemia: pathogenicity and antifungal resistance. J Hosp Infect. 2002;50:243-60.

16. Lacasse A, Cleveland KO. Trichosporon mucoides fungemia in a liver transplant recipient: case report and review. Transpl Infect Dis. 2009;11:155-9.

17. Lee JS, Shin JH, Kim MN, Jung SI, Park KH, Cho D, et al. Kodamaea ohmeri isolates from patients in a university hospital: identification, antifungal susceptibility, and pulsed-field gel electrophoresis analysis. J Clin Microbiol. 2007;45:1005-10.

18. Li L, Redding S, Dongari-Bagtzoglou A. Candida glabrata: an emerging oral opportunistic pathogen. J Dent Res. 2007;86:204-15.
19. Liu H, Miller LG, Hays RD, Golin CE, Zhao H, Wenger NS, et al. A comprehensive evaluation of survey questions for adherence to antiretroviral medications and exploratory analyses for identifying optimal sets of survey questions. AIDS Patient Care STDS. 2006;20:760-72

20. Luque AG, Biasoli MS, Tosello ME, Binolfi A, Lupo S, Mangaró HM. Oral yeast carriage in HIV-infected and non-infected populations in Rosario, Argentina. Mycoses. 2009;52:53-9.

21. Mane A, Pawale C, Gaikwad S, Bembalkar S, Risbud A. Adherence to buccal epithelia cells, enzymatic and hemolytic activities of Candida isolates from HIV-infected individuals. Med Mycol. 2011;49:548-51.

22. Martins JS, Junqueira JC, Faria RL, Santiago NF, Rossoni RD, Colombo CE, et al Antimicrobial photodynamic therapy in rat experimental candidiasis: evaluation of pathogenicity factors of Candida albicans. Oral Surg Oral Med Oral Pathol Oral Radiol Endod. 2011;111:71-7.

23. Melo NR, Taguchi H, Culhari VP, Kamei K, Mikami Y, Smith SN, et al. Oral candidiasi of HIV-infected children undergoing sequential HIV therapies. Med Mycol 2009;47:149-56.

24. Melo NR, Taguchi H, Jorge J, Pedro RJ, Almeida OP, Fukushima K, et al. Oral Candida flora from Brazilian human immunodeficiency virus-infected patients in the highly active antiretroviral therapy era. Mem Inst Oswaldo Cruz. 2004;99:425-31.

25. Menon T, Herrera M, Periasamy S, Palanivelu V, Sikhamani R, Wickes B. Ora candidiasis caused by Kodamaea ohmeri in a HIV patient in Chennai, India. Mycoses. 2010;53:458-9

26. Miceli MH, Díaz JA, Lee SA. Emerging opportunistic yeast infections. Lancet Infect Dis. 2011;11:142-51.

27. Migliorati CA, Birman EG, Cury AE. Oropharyngeal candidiasis in HIV-infected patient under treatment with protease inhibitors. Oral Surg Oral Med Oral Pathol Oral Radiol Endod. 2004;98:301-10

28. Paphitou NI, Ostrosky-Zeichner L, Paetznick VL, Rodriguez JR, Chen E, Rex JH. In vitro antifungal susceptibilities of Trichosporon species. Antimicrob Agents Chemother 2002;46:1144-6.

29. Pires-Gonçalves RH, Miranda ET, Baeza LC, Matsumoto MT, Zaia JE, Mendes-Giannini MJ. Genetic relatedness of commensal strains of Candida albicans carried in the oral cavity of patients' dental prosthesis users in Brazil. Mycopathologia. 2007;164:25563.

30. Price MF, Wilkinson ID, Gentry LO. Plate method for detection of phospholipase activity in Candida albicans. Sabouraudia. 1982;20:7-14.

31. Redding SW, Dahiya MC, Kirkpatrick WR, Coco BJ, Patterson TF, Fothergill AW, $e$ al. Candida glabrata is an emerging cause of oropharyngeal candidiasis in patients receiving radiation for head and neck cancer. Oral Surg Oral Med Oral Pathol Ora Radiol Endod. 2004;97:47-52.

32. Ribeiro PM, Bacal F, Koga-Ito CY, Junqueira JC, Jorge AOC. Presence of Candida spp. in the oral cavity of heart transplantation patients. J Appl Oral Sci. 2011;19:6-10.

33. Ruchell R, Tegeller R, Trost MA. A comparison of secretory proteinases from different strains of Candida albicans. Sabouraudia. 1982;20:233-44.

34. Sandven P, Nilsen K, Digranes A, Tjade T, Lassen J. Candida norvegensis: a fluconazoleresistant species. Antimicrob Agents Chemother. 1997;41:1375-6.

35. Seneviratne CJ, Jin L, Samaranayake LP. Biofilm lifestyle of Candida: a mini review Oral Dis. 2008;14:582-90.

36. Serena C, Mariné M, Pastor FJ, Nolard N, Guarro J. In vitro interaction of micafungin with conventional and new antifungals against clinical isolates of Trichosporon, Sporobolomyces and Rhodotorula. J Antimicrob. Chemother. 2005;55:1020-3. 
JUNQUEIRA, J.C; VILELA, S.F.G.; ROSSONI, R.D.; BARBOSA, J.O.; COSTA, A.C.B.P.; RASTEIRO V.M.C.; SULEIMAN, J.M.A.H. \& JORGE, A.O.C. - Oral colonization by yeasts in HIV-positive patients in Brazil. Rev. Inst. Med. Trop. Sao Paulo, 54(1): 17-24, 2012.

37. Shang ST, Lin JC, Ho SJ, Yang YS, Chang FY, Wang NC. The emerging life-threatening opportunistic fungal pathogen Kodamaea ohmeri: optimal treatment and literature review. J Microbiol Immunol Infect. 2010;3:200-6.

38. Thein ZM, Seneviratne CJ, Samaranayake YH, Samaranayake LP. Community lifestyle of Candida in mixed biofilms: a mini review. Mycoses. 2009;52:467-75.

39. Thompson GR 3rd, Patel PK, Kirkpatrick WR, Westbrook SD, Berg D, Erlandsen J, et al. Oropharyngeal candidiasis in the era of antiretroviral therapy. Oral Surg Oral Med Oral Pathol Oral Radiol Endod. 2010;109:488-95.
40. Yang YL, Hung CC, Wang AH, Tseng FC, Leaw SN, Tseng YTT, et al. Oropharyngeal colonization of HIV-infected outpatients in Taiwan by yeast pathogens. J Clin Microbiol 2010;48:2609-12.

41. Yang YL, Wang AH, Wang CW, Cheng WT, Li SY, Lo HJ, et al. Susceptibilities to amphotericin B and fluconazole of Candida species in Taiwan Surveillance of Antimicrobial Resistance of Yeasts 2006. Diagn Microbiol Infect Dis. 2008;61:175-80.

Received: 12 September 2011

Accepted: 15 December 2011 